\title{
Forearm articular proportions and the antebrachial index in Homo sapiens, Australopithecus afarensis and the great apes
}

\author{
Frank L’Engle Williams ${ }^{\mathrm{a} *}$, Deborah L. Cunningham ${ }^{\mathrm{b}}$, Lia Q. Amaral ${ }^{\mathrm{c}}$ \\ ${ }^{a}$ Department of Anthropology, Georgia State University, 33 Gilmer Street, Atlanta, GA 30303, \\ USA \\ ${ }^{b}$ Department of Anthropology, Texas State University, 601 University Drive, San Marcos, TX, \\ 78666, USA \\ ${ }^{c}$ Department of Applied Physics, Institute of Physics, University of São Paulo, Rua do Matão \\ Travessa R Nr. 187, CEP 05508-090, Cidade Universitária, São Paulo, SP, Brazil
}

Received 30 May 2014, accepted 15 February 2015

*Corresponding author. Tel.: +1-404-413-5154, fax: +1-404-413-5159. E-mail address:

Frankwilliams@gsu.edu (Frank L'Engle Williams) 


\begin{abstract}
With the evolution of bipedalism, the forearms were free to adopt nonlocomotor tasks which may have influenced the articular surfaces of the ulna and the relative lengths of the forearm bones. Similarly, sex differences in forearm proportions may be more likely to emerge in bipeds than in the great apes given the locomotor constraints in Gorilla, Pan and Pongo. To test these assumptions, ulnar articular proportions and the antebrachial index (radius length / ulna length) in Homo sapiens $(\mathrm{n}=51)$, Gorilla gorilla $(\mathrm{n}=88)$, Pan troglodytes $(\mathrm{n}=49)$, Pongo pygmaeus $(\mathrm{n}$ =36) and Australopithecus afarensis A.L. 288-1 and A.L. 438-1 are compared. Interceptadjusted ratios are used to control for size and minimize the effects of allometry. Canonical scores axes show that the proximally broad and elongated trochlear notch with respect to size in H. sapiens and A. afarensis is largely distinct from G. gorilla, P. troglodytes and P. pygmaeus. A cluster analysis of scaled ulnar articular dimensions groups $H$. sapiens males with A.L. 438-1 ulna length estimates, while one A.L. 288-1 ulna length estimate groups with Pan and another clusters most closely with H. sapiens, G. gorilla and A.L. 438-1. The relatively low antebrachial index characterizing $H$. sapiens and non-outlier estimates of A.L. 288-1 and A.L. 438-1 differs from those of the great apes. Unique sex differences in H. sapiens suggest a link between bipedality and forearm functional morphology.
\end{abstract}

\title{
Introduction
}

Humans have relatively short forearms compared to those in the great apes. Several explanations have been advanced to explain the evolution of short forearms in humans, including long-distance running (Bramble and Lieberman, 2004), carrying food (Hewes, 1961; Lovejoy, 1981; Sinclair, 1986; Videan and McGrew, 2002) and carrying infants (Williams et al., 2010). Hominin upper limbs became available for non-locomotor uses at the advent of bipedality, freeing them for tasks that in turn shaped their morphology (Tocheri et al., 2007). Humanlike brachial proportions are observed in Australopithecus afarensis (Richmond et al., 2002), and the upper limb proportions for A. afarensis appear to be within the range of humans albeit with a slightly longer ulna (Drapeau and Ward, 2007). Specimen A.L. 288-1 exhibits a marginally longer humerus than typical for a human of small body size (Holliday and Franciscus, 2012). The continued use of the forelimbs for locomotion in arboreal habitats would have necessitated 
the maintenance of some adaptations related to joint mobility and stability. However, if nonlocomotor tasks became the dominant function of the forearms, changes in the relationship between the ulna and radius and joint stress may have occurred, consequently affecting articular surface morphology (Pal and Routal, 1991).

\section{Forearm carrying}

Although the forearm is also recruited during throwing, climbing, signaling, foraging and social activities, one of the primary nonlocomotor uses of the forearm among humans is carrying. Forearm carrying results in flexion of the elbow which functions as a third class lever system (Amis, 2002; Jazrawi et al., 1985). The three muscles that serve to stabilize and flex the elbow are biceps brachii, brachialis and brachioradialis. Brachialis is the primary flexor of the elbow, along with biceps brachii which also serves to supinate the forearm. Brachioradialis is recruited to increase the rapidness and power of elbow flexion, as well as to stabilize the flexed forearm (Aiello and Dean, 1992). During flexed forearm carrying, the amount of force or resistance exerted by the flexor muscles is predicated by the distance between the fixed point of the fulcrum, or ulnar trochlear notch, and the load arm, where weight bearing occurs.

Nonlocomotor tasks also involve the rotation of the wrist during pronation and supination. These actions involve the ulnar radial notch and carpal head of the ulna as the proximal and distal rotation surfaces of the radius. It is reasonable to assume that only major changes related to locomotor use, body size and/or very specific behaviors would alter the dimensions of these two articular surfaces between the ulna and radius.

Additionally, the relationship between the lengths of the ulna and radius would potentially be modified during flexed forearm carrying and other nonlocomotor tasks in hominins. These changes include a modification of the angulation and size of the distal articulation of the radius, the lengths of the styloid processes of the radius and ulna as well as the projection of the olecranon process, all of which are different between apes and humans. However, the length of the ulna can also vary independent of radius length through an extension of the trochlear notch,

enhancing the mechanical advantage of forearm carrying. Distal elongation of the trochlear notch results in a center of rotation that would be slightly further away from the muscle insertions.

\section{Sex differences}


The diminutive A.L. 288-1 and very large and robust A.L. 438-1 likely correspond to female and male representatives of $A$. afarensis, respectively (Drapeau et al., 2005; Kimbel et al., 1994; cf. Haeusler and Schmid, 1995; Tague and Lovejoy, 1998). Sex differences in A. afarensis have been investigated by a number of researchers (Gordon, 2006; Gordon et al., 2008; Greenfield, 1992; Harmon, 2006; Kimbel and White, 1988; Lague, 2002; Lovejoy et al., 1989; McHenry, 1992; Plavcan, 2000; Plavcan et al., 2005; Plavcan and van Schaik, 1997; Reno et al., 2003, 2005; Richmond and Jungers, 1995). Some posit multiple species rather than sex differences characterize the remains (Senut et al., 2001; Senut and Tardieau, 1985).

Differences in forearm proportions could signal potential functional dissimilarities between hominins and the great apes and between female and male hominins. Forearm bones of $A$. afarensis can demonstrate the evolutionary significance of these differences. However, published forearm limb bone length estimates vary widely, particularly for A.L. 288-1. Given the potential nonlocomotor function of the forearms in bipeds, we expect $H$. sapiens and A. afarensis to be distinct from the great apes. Similarly, we also anticipate that forearm proportions will differ between the sexes only in $H$. sapiens.

\section{Materials and Methods}

The sample includes Homo sapiens $(\mathrm{n}=51)$, Gorilla gorilla $(\mathrm{n}=88)$, Pan troglodytes $(\mathrm{n}=$ $49)$ and Pongo pygmaeus $(\mathrm{n}=36)$. Measurements on wild ape and human remains were taken at the Cleveland Museum of Natural History (Cleveland, $\mathrm{OH}$ ), the Smithsonian Institution of Natural History (Washington, DC), the American Museum of Natural History (New York), the Museum of Comparative Zoology at Harvard University (Cambridge, MA), the Field Museum (Chicago), the University of Tennessee (Knoxville), the British Museum (London), the Anthropological Institute of Zurich and the Zoological Museum of Zurich. The human sample is from Africa and North America. The African sample is historic and includes 18 individuals from South Africa, three Nubians from Egypt and one individual each from German East Africa, the Congo and Liberia. The North American sample is prehistoric and includes 22 Arikara and five Grand Gulch individuals. Bone lengths were measured using an osteometric board while joint surface dimensions were taken with digital calipers (Table 1; Fig. 1).

Articular surface dimensions on the original A.L. 288-1 and a cast of A.L. 438-1 were measured at the National Museum of Ethiopia (Addis Ababa). The high-quality primary cast of 
A.L. 438-1 represents only minor differences in ulnar articular dimensions from the original fossil and is therefore suitable for analysis. There is temporal variation between these two fossils as A.L. 288-1 is dated to 3.18 Ma and A.L. 438-1, one of the geologically youngest specimens attributed to A. afarensis, is dated to 3.0 Ma (Drapeau et al., 2005; Johanson et al., 1982; Johanson and Taieb, 1976; Kimbel et al., 1994, 2004).

When flexed forearm carrying occurs, three ulnar articular surfaces are recruited, including the (1) trochlear notch, where the ulna accommodates the distal humerus, (2) the radial notch, where the ulna articulates with the proximal radius, and (3) the ulnar head, where the ulna accommodates the distal radius. Articular surfaces define the range of movement and joint stability during recruitment. It has been shown that the surface area of a limb bone joint can be accurately approximated by a standard linear dimension (Ruff, 2002). One advantage of using standard linear dimensions is that they can be scaled to limit the effects of size. This is a particularly important consideration when comparing A.L. 288-1 to extant hominoids. The three ulnar articular surfaces are approximated by eight linear dimensions (Cunningham, 2005; Ruff, 2002) (Fig. 1). Three of these serve as proxies for the breadth of the trochlear notch given its variable widths, whereas one dimension captures the proximodistal length of this joint surface; the radial notch is approximated by its anteroposterior and proximodistal lengths; and the ulnar head by its mediolateral and anteroposterior dimensions, and all of these are divided by ulna length to control for size differences. Ulna length is used to scale for size in order to directly compare various competing hypotheses regarding the absolute dimensions of this forearm bone in the fossils (Table 2).

We develop an "antebrachial index" (radius length / ulna length) to compare hominins and the great apes and to identify potential differences between the sexes. The index also allows for the direct comparison of radius-ulna composites from estimates of A.L. 288-1 and A.L. 438-1 forearm limb bone lengths (Table 2).

INSERT Tables 1, 2 AND Fig. 1 ABOUT HERE

\section{Fossil long bone length estimates}


An estimate of the maximum ulna length for A.L. 288-1 of $220 \mathrm{~mm}$ was provided by Kimbel et al. (1994) while Haeusler and McHenry (2004) reported a minimum ulna length of $191 \mathrm{~mm}$ for AL 288-1 (Table 2).

For the radius of A.L. 288-1, there are three length estimates published. The smallest is 174 mm [Schmid (1983) as cited in Hartwig-Scherer and Martin (1991) and Richmond et al. (2002)]; intermediate is $203 \mathrm{~mm}$ (Asfaw et al., 1999); and the largest is $215 \mathrm{~mm}$ (Asfaw et al., 1999). According to Richmond et al. (2002:533) and Hartwig-Scherer and Martin (1991:440), the short Schmid (1983) estimate is "humanlike" although how this was determined is never communicated (Schmid, 1983). The long radius estimate of $215 \mathrm{~mm}$ was based on a regression using a sample of Pan troglodytes and P. paniscus (Asfaw et al., 1999). These authors originally used a sex- and species-balanced sample of Pan, Gorilla and Homo that resulted in a shorter radius length of $203 \mathrm{~mm}$ for A.L. 288-1. However, Asfaw et al. (1999) claim that this length (203 $\mathrm{mm}$ ) is improbable given the missing pieces of the radial shaft, and they prefer the long estimate of $215 \mathrm{~mm}$ based on the Pan regression. Haeusler and McHenry (2007) disagree with this long estimate of radius length $(215 \mathrm{~mm})$, arguing that longitudinal cracks in the fossils explain the discrepancy in shaft thickness between the fragments that influenced Asfaw et al. (1999), and suggest that there is no independent reason why a chimpanzee regression model should be preferred for A.L. 288-1. We compare all combinations of radius and ulna length estimates for A.L. 288-1. These include (a) long radius length from Asfaw et al. (1999) with ulna length from Haeusler and McHenry (2004); (b) long radius length from Asfaw et al. (1999) with ulna length from Kimbel et al. (1994); (c) short radius length from Asfaw et al. (1999) with ulna length from Haeusler and McHenry (2004); (d) short radius length from Asfaw et al. (1999) with ulna length from Kimbel et al. (1994); (e) radius length from Schmid (1983) with ulna length from Haeusler and McHenry (2004); and (f) radius length from Schmid (1983) with ulna length from Kimbel et al. (1994).

The A.L. 438-1 partial skeleton includes a complete ulna that provides a maximum length reported as $278 \mathrm{~mm}$ by Drapeau et al. (2005) and as $268 \mathrm{~mm}$ by Kimbel et al. (1994) (Table 2). This $10 \mathrm{~mm}$ discrepancy is likely the result of the exclusion of the styloid process in the maximum length measurement of A.L. 438-1 (Kimbel et al., 2005). The A.L. 438-1 partial skeleton only preserves a small portion of the proximal radial diaphysis (Drapeau et al., 2005). To further compare the ulna length estimates for A.L. 438-1 from Drapeau et al. (2005) and 
Kimbel et al. (1994), radius length was estimated using linear regression. Specifically, radius length was regressed against ulna length using all extant hominoids included in this study $(\mathrm{n}=$ 224). The resulting radius length estimate of $258.9 \mathrm{~mm}$ for A.L. 438-1 was compared to the ulna length reconstructions from Drapeau et al. (2005) and from Kimbel et al. (1994) in calculations of the antebrachial index. Although circularity is inherent in comparing an estimate to the sample from which it is drawn, given fossil preservation it may not be possible to use an entirely independent estimate of antebrachial proportions for any A. afarensis specimen.

\section{Controlling for size and allometry}

The small size of A.L. 288-1 compared to all other individuals in the study is problematic with respect to scaling. There are many ways to control for size (Albrecht et al., 1993; Corruccini, 1977). We chose to scale each raw measurement (Table 1) using ulna length so that published ulna length estimates for A.L. 288-1 and A.L. 438-1 could be included. In this way we test multiple hypotheses of ulna length with respect to the articular surfaces associated with these fossils.

One caveat in the use of ratios to control for size is that if the relationship between an articular dimension and size is allometric rather than isometric, then ratios can produce erroneous results (Franks and Cabo, 2014). In other words, if a linear approximation of the relationship between two variables in Equation 1 exhibits a nonzero slope, potential allometric artifacts may be inadvertently introduced into the comparison (Albrecht et al., 1993; Franks and Cabo, 2014). In Equation 1, where raw measurement $(y)$ is compared in a linear regression to size $(x),(a)$ is the $y$-intercept and $(b)$ is the slope or coefficient. When the relationship between $(y)$ and $(x)$ is linear, which is the case for our data, the exponent of size $(k)=1$, resulting a simple linear relationship between $(y)$ and $(x)$.

$$
y=a+b x \quad \text { (1) }
$$

When a nonzero slope $(b)$ is present in the linear relationship between $(y)$ and $(x)$, the two variables are not independent (Franks and Cabo, 2014). Furthermore, Albrecht et al. (1993) maintain that size $(x)$ should be uncorrelated with $(y / x)$. In order to control for allometric distortion in the shape ratios, the original measurements were regressed against ulna length $(x)$, and the y-intercept $(a)$ of this relationship was subsequently subtracted from the measurement 
before a ratio $(y / x)$ was constructed yielding yxadj (Albrecht et al., 1993). To ensure that the coefficient was zero for these intercept-adjusted ratios ( $y x a d j)$ they were regressed against ulna length and the resulting slopes $(b)$ ranged from zero to -0.001 (Fig. 2).

$$
y x a d j=(y-a) / x \quad 2
$$

A zero coefficient produces a flat line regression between ( yxadj) and $(x)$ indicative of isometry (Fig. 2) (Albrecht et al., 1993). Correlation coefficients for all y-intercept adjusted ratios $(y x a d j)$ ranged from 0.038 to -0.039 , thus nearly zero suggesting that the allometric effects were removed, and that these intercept-adjusted ratios (yxadj) were virtually uncorrelated with ulna length $(x)$, or size as demonstrated in Figure 2 (Albrecht et al., 1993; Franks and Cabo, 2014). These intercept-adjusted ratios of ulnar articular dimensions ( $y x U V a d j$ ) were used in subsequent analyses.

To calculate the antebrachial index while avoiding potential allometric effects from the creation of a ratio, radius length $(y)$ was first regressed against ulna length $(x)$ as shown in Equation 1, and the resulting y-intercept $(a)$ subtracted from radius length $(y)$ before dividing by ulna length $(x)$ as shown in Equation 2 resulting in an intercept-adjusted antebrachial index (yxRUadj) (Albrecht et al., 1993; Corruccini, 1977).

\section{INSERT Fig. 2 ABOUT HERE}

\section{Methods of analyses}

Classification rates were obtained from a discriminant function analysis of the scaled ulnar articular dimensions ( $y x U V a d j)$ and ulna length (UL) using four estimates of ulna length from two $A$. afarensis individuals, which were treated as a group $(\mathrm{n}=4)$. Ulna length (UL) was included to reintroduce size on the first multivariate axis, further diminishing the effect of sizecorrelated shape on the second multivariate axis (Franks and Cabo 2004). To identify whether 
group distinctions exist, individuals were plotted on canonical scores axes with confidence ellipses surrounding $68 \%$ of the sample for each taxon.

To further identify whether the hominins are distinct from the great apes and whether the sexes of each taxon differ, the eight intercept-adjusted scaled articular ulna dimensions $(y x U V a d j)$ were subjected to a cluster analysis using the mean for each female and male per taxon, and four ulna length estimates for A. afarensis (A.L. 288-1 and A.L. 438-1).

To address whether H. sapiens and the great apes show differences in the antebrachial index ( $y x R U a d j$ ), each of the great ape taxa are compared to H. sapiens using ANOVA with Tukey's honestly significant differences post-hoc test. A box and whiskers graph compares the antebrachial index in extant taxa, six A.L. 288-1 estimates and two A.L. 438-1 estimates (Table 2).

T-tests are employed to identify significant sex differences within each extant taxon in scaled ulnar articular surface dimensions ( $y x U V a d j)$ and the antebrachial index ( $y x R U a d j)$.

\section{Results}

Descriptive statistics of each of the scaled ulnar articular dimensions ( $y x U V a d j)$ and the antebrachial index ( $y x R U a d j$ ) demonstrate differences exist across the taxa and between the sexes within each taxon (Table 3 ).

\section{Distinctions in ulnar proportions}

A discriminant function analysis yields classification rates which are highest for G. gorilla and P. pygmaeus (100\%), followed by H. sapiens males (81\%) and females (72\%) (Table 4). The lowest classification rates are for $P$. troglodytes females $(69 \%)$ and males $(68 \%)$ and $A$. afarenesis (50\%). The two estimates for A.L. 438-1 are misclassified as H. sapiens males. Misclassifications among $H$. sapiens and P. troglodytes also exist, but individuals are misclassified as the opposite sex within the same taxon suggesting distinctions between females and males are minor compared to species-specific differences. For jack-knifed classification rates, $A$. afarensis remains at 50\% since the two A.L. 438-1 estimates are again misclassified as H. sapiens males (Table 4). 


\section{INSERT Tables 3 and 4 ABOUT HERE}

Two canonical scores axes with eigenvalues greater than one, generated from the discriminant function analysis of scaled ulnar articular dimensions ( $y x U V a d j)$ and ulna length (UL) collectively account for $93.8 \%$ of the variance (Fig. 3). The first axis represents $72 \%$ of the variance and separates $G$. gorilla males and to a lesser extent, $P$. pygmaeus males, from $H$. sapiens and A. afarensis. Females of G. gorilla and P.pygmaeus, as well as P. troglodytes, are projected between these two extremes. The fossil estimate for A.L. 288-1 using Haeusler and McHenry's (2004) ulna length falls close to the distribution for H. sapiens. In contrast, the fossil estimate for the ulna length of A.L. 288-1 from Kimbel et al. (1994) is an outlier, being comparatively distant from $H$. sapiens and indeed from all other extant taxa. The ulna length estimate from Drapeau et al. (2005) falls within the 68\% sample confidence ellipse for $H$. sapiens males. The estimate for A.L. 438-1 based on the ulna length from Kimbel et al. (1994) falls within the $68 \%$ sample confidence ellipse for $H$. sapiens males, but on the periphery of the confidence ellipse for P. troglodytes males (Fig. 3).

On the first axis, high positive values characterize the canonical discriminant functions standardized by within-group variances for scaled trochlear notch height ( $y x U V 4 a d j)$ and scaled proximal width of the trochlear notch ( $y x U V 1 a d j)$. These contrast with ulna length (UL), scaled distal width of the trochlear notch ( $y x U V 3 a d j)$, and scaled mediolateral width of the ulnar head ( $y x U V 7 a d j)$ with high negative values on the first axis (Table 5). Homo sapiens and $A$. afarensis have relatively elongated and distally wide trochlear notches compared to the great apes. The mediolateral breadth of the ulnar head $(y x U V 7 a d j)$ is smaller with respect to size in humans, but less so in A. afarensis while ulna length is reduced in hominins compared to the great apes, particularly in A.L. 288-1. On the second axis, a mediolaterally enlarged distal ulna ( $y x U V 7 a d j)$ and relatively long ulna length (UL) explain the negative projection of $P$. pygmaeus while the relatively expanded proximal trochlear notch width with respect to size $(y x U V 1 a d j)$ and pronounced length of the trochlear notch (yxUV4adj) in G. gorilla, H. sapiens and A. 
afarensis largely accounts for their positive projection (Table 5), as well as the separation of $P$. troglodytes and H. sapiens.

\section{INSERT Fig. 3 AND Table 5 ABOUT HERE}

A cluster analysis of ulnar articular dimensions ( $y x U \mathrm{Vadj}$ ) shows that some of the shortest distances are between the sexes of great ape taxa, particularly P. troglodytes and P. pygmaeus. In H. sapiens, the sexes are less similar to each other (Fig. 4). Pongo pygmaeus is clearly distinct from the other taxa followed by P. troglodytes. Gorilla gorilla, H. sapiens and A. afarensis are clustered together with the Haeusler and McHenry (2004) ulna length estimate for A.L. 288-1, while the Kimbel et al. (1999) ulna length estimate for A. L. 288-1 clusters with Pan by a relatively long branch. The shortest distances are between the A.L. 438-1 estimates from Drapeau et al. (2008) and Kimbel et al. (1994) which are clustered with H. sapiens males followed by $H$. sapiens females.

INSERT Fig. 4 ABOUT HERE

\section{Distinctions in the antebrachial difference}

An ANOVA of the antebrachial index ( $y x R U a d j$ ) yields a significant difference among the taxa $(\mathrm{F}=40.874 ; p<0.001)$. The results of Tukey's post-hoc test demonstrate that all of the great ape taxa are significantly different from $H$. sapiens (Table 6). Among the great apes, all are significantly different from one another with the exception of $P$. troglodytes and P. pygmaeus (Table 6).

INSERT Table 6 ABOUT HERE

Sex differences within humans and the great apes 
Significant sex differences are pronounced in H. sapiens and G. gorilla (Table 6). All taxa exhibit significant differences in scaled length of the trochlear notch of the ulna ( $y x U V 4 a d j)$, and all except $P$. pygmaeus show significant distinctions in the intercept-adjusted antebrachial index ( $y x R U a d j)$. Furthermore, both H. sapiens and G. gorilla exhibit significant sex differences in scaled mediolateral breadth of the distal ulna ( $y x U V 7 a d j)$. In $H$. sapiens, the sexes significantly differ in scaled distal breadth of the trochlear notch $(y x U V 3 a d j)$. For the scaled proximal breadth of the trochlear notch ( $y x U V 1 a d j)$, the sexes are significantly different in $G$. gorilla and P. pygmaeus. However, for the great apes, males are larger than females in all of these significant differences $(y x U V a d j)$. In contrast, for the three articular variables which show significant sex differences in H. sapiens (Table 6), it is females who are relatively larger. Specifically, in the ulna, human females exhibit relatively longer but distally broader trochlear notches, with respect to size, as well as proportionally wider mediolateral breadths of the ulna head compared to males (Table 6). For the antebrachial index ( $y x$ RUadj) the opposite pattern prevails such that $H$. sapiens females show a significantly shorter radius with respect to ulna length compared to H. sapiens males, whereas in the African apes, it is females which show a significantly longer radius length with respect to ulna length (Table 6; Fig. 5).

\section{Forearm limb bone lengths for A.L. 288-1 and A.L. 438-1}

A number of competing hypotheses have been published concerning the length of the radius and ulna in A.L. 288-1, and the ulna in A.L. 438-1. For the scaled ulna articular dimensions ( $y x U V a d j$ ) of A.L. 288-1, Hausler and McHenry's (2004) ulna length estimate of $191 \mathrm{~mm}$ falls within the range of $H$. sapiens females and males on PC Axis 2 suggesting fundamental similarities in ulna articular shape, while the ulna length estimate of $220 \mathrm{~mm}$ from Kimbel et al. (1994) is an outlier on PC Axis 2 suggesting an ulna that differs from the other fossil estimates (Fig. 3). The A.L. 438-1 ulna length estimate of $278 \mathrm{~mm}$ provided by Drapeau et al. (2005) is similar to that of H. sapiens males, while that of $268 \mathrm{~mm}$ from Kimbel et al. (1994) falls into the ranges of both $H$. sapiens and $P$. troglodytes males (Fig. 3). 
For the intercept-adjusted antebrachial index ( $y x R U a d j$ ), eight pairs of fossil radius and ulna length estimates are examined. The long radius length estimate from Asfaw et al. (1999) appears to be too large for either ulna length reconstructions of A.L. 288-1 as shown in (a) and (b) (Fig. 5). In contrast, the short radius length of $203 \mathrm{~mm}$ from Asfaw et al. (1999) falls within the range of extant hominoids if paired with the ulna length of $220 \mathrm{~mm}$ from Kimbel et al. (1994) as shown in (d) (Fig. 5). Similarly the Schmid (1983) estimate of radius length for A.L. 288-1 of $174 \mathrm{~mm}$ falls within the range of extant hominoids if paired with Haeusler and McHenry's (2004) ulna length of $191 \mathrm{~mm}$ as shown in (e) (Fig. 5). Both (d) and (e) fall within the range of H. sapiens, whereas the Schmid (1983) radius length paired with the ulna length of Kimbel et al. (1994) (f) is unrealistically low (Fig. 5).

With respect to A.L. 438-1, the radius estimate from this study, $259.3 \mathrm{~mm}$, paired with the ulna length of $268 \mathrm{~mm}$ from Kimbel et al. (1994) falls outside the range of extant hominoids as shown in (g) (Fig. 5). However, the radius estimate from this study combined with ulna length of $278 \mathrm{~mm}$ from Drapeau et al. (2005) falls within the range of $H$. sapiens males as shown in (h) (Fig. 5).

\section{INSERT Table 6 AND Fig. 5 ABOUT HERE}

\section{Discussion}

Australopithecus afarensis exhibits substantial size differences in ulnar dimensions as demonstrated by the variation between A.L. 288-1 and A.L. 438-1 (Drapeau et al., 2005). However, shape variation is not extreme in A. afarensis (Table 2). Multivariate analyses of scaled ulnar articular dimensions (yxUVadj) of A.L. 288-1 and A.L. 438-1 are similar to one another, particularly on canonical scores axis 2 (Fig. 3) and are similar to H. sapiens (Figs. 3 and 4). These observations agree with Drapeau et al. (2005) who suggest A.L. 288-1 and A.L. 438-1

ulnae exhibit similar functional capabilities, and that differences exist in size but not in indices of shape.

When the antebrachial index ( $y x R U a d j$ ) is considered, valid estimates for $A$. afarensis are similar to H. sapiens and largely distinct from the great apes (Fig. 5). Homo sapiens females are 
significantly smaller than males in the antebrachial index ( $y x R U a d j)$ whereas the reverse is true for the African apes such that males are significantly smaller than females (Table 5; Fig. 5). This pattern suggests that distinct sex differences in antebrachial proportions exist, and that habitual bipeds are largely distinct from the African apes (Fig. 5).

Additionally, three out of eight variables (yxUV3adj), (yxUV4adj) and (yxUV7adj) show significant differences. Females of $H$. sapiens exhibit relatively elongated and distally broad trochlear notches, and relatively wide mediolateral dimensions of the distal ulna with respect to size. In contrast, great ape males are significantly larger than females for several scaled ulna articular dimensions (Table 6). Lague and Jungers (1999), in an analysis of the distal humerus among hominoids, also found significant sexual dimorphism in the elbow joint of western lowland gorillas (G. g. gorilla) which they attribute to greater load-bearing behavior of males compared to females. In contrast, the differences in scaled ulnar articular dimensions between female and male $H$. sapiens are not due to locomotor requirements, suggesting other factors must be responsible for these sex distinctions.

\section{The forearms of early hominins}

The forearms became increasingly available for non-locomotor functions during the transition to bipedality and this could have contributed to sex differences in forearm use since locomotor constraints were removed. This would occur only if non-locomotor functions of the forearms were more important than locomotor ones and if these adaptations for new functions had become essential for survival (cf. Jungers, 1982; Latimer, 1991; Latimer et al., 1987; Ohman et al., 1997; Stern, 2000; Stern and Susman, 1983; Ward, 2003; Ward et al., 2011). The argument can be made that these new functions required morphological changes at the expense of adaptations to arboreality. The intermediate form of the trochlear notch in A. afarensis indicates both terrestrial and arboreal substrates may have been exploited (Drapeau, 2008). Drapeau and Ward (2007) conclude that $A$. afarensis was under selection to reduce the length of its upper limb segments, perhaps related to a relaxation of selection for arboreality combined with positive selection for an activity that favored shorter forelimbs. This activity may have been carrying behavior. Although energetically costly for early australopiths (Wang et al., 2003), carrying was still possible, and 
perhaps one of the most important functions, among many others (Alba et al., 2003), of the freed hands (Darwin, 1871; Hewes, 1961; Videan and McGrew, 2002).

Human-like antebrachial proportions and short forelimbs may have adaptive value for habitual bipedalism and carrying behavior in terrestrial environments. Although sex-specific differences in foraging and feeding behavior may explain some of the differences in extant apes, it is also apparent that gorillas and humans are similar in the antebrachial index, but not orangutans which are also sexually dimorphic, but not necessarily in relative forearm bone lengths. Perhaps it is the terrestriality of H. sapiens and G. gorilla which explains some of the similarities in the forearm bones (Knussmann, 1967), although for the antebrachial index ( $y x R U a d j$ ), females exhibit shorter radii in H. sapiens, whereas the African apes exhibit the reverse configuration. Additionally, in scaled articular dimensions of the ulna, females are larger than males for several traits, whereas for the great apes, where significant differences are present, it is males which exhibit the larger values suggesting sex differences in behavior.

Sex-specific patterns of foraging and feeding behavior may explain some of the differences in extant apes and humans. The sexes of G. gorilla are reported to exhibit differences in foraging and positional behavior with silverback males showing more terrestrial postures during feeding than females (Remis, 1995, 1999; Schaller, 1963). Foraging differences are known to exist in $P$. pygmaeus where ecological selection has resulted in two very different body sizes and diets in females compared to males (Cant, 1987; Sugardjito and van Hooff, 1986). Sex-specific foraging differences have been reported in P. troglodytes including a relatively greater amount of time devoted to foraging for insects in females and a greater consumption of mammalian meat in males (McGrew, 1992; Stanford, 1998). However, it is H. sapiens which stands out as exhibiting the most unique sex differences in forearm proportions. A variety of behaviors may have influenced sex differences in hominins including forearm carrying of infants (Williams et al., 2010), tool use and cultural modification, manipulative activities, social signaling, foraging differences, occupational stress, and other behaviors.

Competing hypotheses of radius length for A.L. 288-1 suggest that the long estimate from Asfaw et al. (1999) may overestimate this forearm bone, whereas that the short estimate of 203 mm from Asfaw et al. (1999), if paired with the ulna length of $220 \mathrm{~mm}$ from Kimbel et al. (1994), results in an individual which falls within the range of extant hominoids in the antebrachial index (Fig. 5). However, when used alone, the Kimbel et al. (1994) ulna length 
estimate for A.L. $220 \mathrm{~mm}$ is an outlier (Fig. 3). The ulna length estimate of $191 \mathrm{~mm}$ from Haeusler and McHenry (2004) results in a much more humanlike ulna articular surface (Fig. 3). Additionally, the Haeusler and McHenry (2004) ulna length estimate for A.L. 288-1, when coupled with the radius length of $174 \mathrm{~mm}$ originally from Schmid (1983), falls within the range of H. sapiens (Fig. 5). The ulna length estimate for A.L. 438-1 from Drapeau et al. (2005) resembles H. sapiens males to a greater extent than the one from Kimbel et al. (1994) (Fig. 3). These findings indicate a short humanlike forearm in both A.L. 288-1 and A.L. 438-1 (Haeusler and McHenry, 2004; Schmid, 1983).

\section{Acknowledgments}

Data collection (DLC) was supported by NSF BCS-0234193, P.E.O., Sigma Xi and the American Museum of Natural History. DLC thanks the curators of the Cleveland Museum of Natural History, American Museum of Natural History, Smithsonian National Museum of Natural History, the Museum of Comparative Zoology, the Field Museum, the University of Tennessee, the British Museum, the Royal Museum of Central Africa, the Anthropological Institute of Zurich, the Zoological Museum of Zurich, and the National Museum of Ethiopia. LQA thanks Drs. Marcos Duarte and Viviana Gianpaoli for discussions on, respectively, biomechanics and statistics. The authors thank Daniel Wescott for valuable comments and Monique McGee for assistance with Figures 2, 3 and 5.

\section{References}

Alba, D.M., Moyà-Solà S., Köhler M., 2003. Morphological affinities of the Australopithecus afarensis hand on the basis of manual proportions and relative thumb length. J. Hum. Evol. 44, 225-254.

Albrecht, G.H., Gelvin, B.R., Hartman, S.E., 1993, Ratios as a size adjustment in morphometrics. Am. J. Phys. Anthropol. 91, 441-468.

Asfaw, B., White, T., Lovejoy, O., Latimer, B., Simpson, S., Suwa, G., 1999. Australopithecus garhi: a new species of early hominid from Ethiopia. Science 284, 629-635.

Bramble, D.M., Lieberman, D.E., 2004. Endurance running and the evolution of Homo. Nature $432,345-352$. 
Cant, J.G., 1987. Effects of sexual dimorphism in body size on feeding postural behavior of Sumatran orangutans (Pongo pygmaeus). Am. J. Phys. Anthropol. 74, 143-148.

Corruccini, R.S., 1977. Correlation properties of morphometric ratios. Syst. Zool. 26, 211-214.

Cunningham, D.L., 2005. Postcranial Proportional Variation in Australopithecus. Ph.D. dissertation, University of Missouri, Columbia.

Darwin, C., 1871. The Descent of Man and Selection in Relation to Sex. Charles Murray, London.

Drapeau, M.S.M., 2008. Articular morphology of the proximal ulna in extant and fossil hominoids and hominins. J. Hum. Evol. 55, 86-102.

Drapeau, M.S.M., Ward, C.V., 2007. Forelimb segment length proportions in extant hominoids and Australopithecus afarensis. Am. J. Phys. Anthropol. 132, 327-343.

Drapeau, M.S.M., Ward, C.V., Kimbel, W.H., Johanson, D.C., Rak, Y., 2005. Associated cranial and forelimb remains attributed to Australopithecus afarensis from Hadar, Ethiopia, J. Hum. Evol. 48, 593-642.

Franks, E.R., Cabo, L.L., 2014. Quantifying asymmetry: ratios and alternatives. Am. J. Phys. Anthropol. 154, 498-511.

Greenfield, L.O., 1992. Origin of the human canine: a new solution to an old enigma. Yrbk. Phys. Anthropol. 35, 153-185.

Gordon, A.D., 2006. Scaling of size and dimorphism in primates II: macroevolution. Intl. J. Primatol. 27, 63-105.

Gordon, A.D., Green, D.J., Richmond, B.G., 2008. Strong postcranial size dimorphism in Australopithecus afarensis: results from two new resampling methods for multivariate data sets with missing data. Am. J. Phys. Anthropol. 136, 311-328.

Harmon, E.H., 2006. Size and shape variation in Australopithecus afarensis proximal femora. J. Hum. Evol. 51, 217-227.

Hartwig-Scherer, S., Martin, R.D., 1991. Was "Lucy" more human than her "child"? Observations on early hominid postcranial skeletons. J. Hum. Evol. 21, 439-449.

Haeusler, M., McHenry, H.M., 2004. Body proportions of Homo habilis reviewed. J. Hum. Evol. $46,433-465$.

Haeusler, M., McHenry, H.M., 2007. Evolutionary reversals of limb proportions in early hominids? Evidence from KNM-ER 3735 (Homo habilis). J. Hum. Evol. 53, 383-405. 
Haeusler, M., Schmid, P., 1995. Comparison of the pelvis of Sts 14 and A.L. 288-1: implications for birth and sexual dimorphism in australopithecines. J. Hum. Evol. 29, 363-383.

Hewes, G., 1961. Food transport and the origin of hominid bipedalism. Am. Anthropol. 63, 687710.

Holliday, T.W., Franciscus, R.G., 2012. Humeral length allometry in African hominids (sensu lato) with special reference to A.L. 288-1 and Liang Bua 1. PaleoAnthropol. 2012, 1-12.

Johanson, D.C., Lovejoy, C.O., Kimbel, W.H., White, T.D., Ward, S.C., Bush, M.E., Latimer, B.M., Coppens, Y., 1982. Morphology of the Pliocene partial hominid skeleton (A.L. 288-1) from the Hadar Formation, Ethiopia. Am. J. Phys. Anthropol. 57, 403-451.

Johanson, D.C., Taieb, M., 1976. Plio-Pleistocene hominid discoveries in Hadar, Ethiopia. Nature 260, 293-297.

Jungers, W.L., 1982. Lucy's limbs: skeletal allometry and locomotion in Australopithecus afarensis. Nature 297, 676-678.

Kimbel, W.H., Johanson, D.C., Rak, Y., 1994. The first skull and other new discoveries of Australopithecus afarensis at Hadar Ethiopia. Nature 368, 449-451.

Kimbel, W.H., White, T.D., 1988. Variation, sexual dimorphism and the taxonomy of Australopithecus. In: Grine, F. (Ed.) Evolutionary History of the "Robust" Australopithecines. Aldine de Gruyter, New York, pp. 175-191.

Knussmann, R., 1967. Humerus, Ulna und Radius der Simiae. Vergleichend-morphologische Untersuchungen mit Berücksichtigung der Funktion. Bibliotheca Primatologica 5, I-IX, 1399.

Lague, M.R., 2002. Another look at shape variation in the distal femur of Australopithecus afarensis: implications for taxonomic and functional diversity at Hadar. J. Hum. Evol. 42, 609-626.

Lague, M.R., Jungers, W.L., 1999. Patterns of sexual dimorphism in the hominoid distal humerus. J. Hum. Evol. 36, 379-399.

Latimer, B., 1991. Locomotor adaptations in Australopithecus afarensis: the issue of arboreality. In: Coppens, Y., Senut, B. (Eds.) Origine(s) de la Bipedie Chez Les Hominidés. Editions du CNRS, Paris, pp. 169-176.

Latimer, B., Ohman, J.C., Lovejoy, C.O., 1987. Talocrural joint in African hominoids: implications for Australopithecus afarensis. Am. J. Phys. Anthropol. 74, 155-175. 
Lockwood, C.A., Richmond, B.G., Jungers, W.L., Kimbel, W.H., 1996. Randomization procedures and sexual dimorphism in Australopithecus afarensis. J. Hum. Evol. 31, 537-548. Lovejoy, C.O., 1981. The origin of man. Science 211, 341-350.

Lovejoy, C.O., Kern, K.F., Simpson, S.W., Meindl, R.S., 1989. A new method for estimation of skeletal dimorphism in fossil samples with an application to Australopithecus afarensis. In: Giacobini. G. (Ed.), Hominidae. Jaka Book, Milan, pp. 103-108.

McGrew, W.C., 1992. Chimpanzee Material Culture: Implications for Human Evolution. Cambridge University Press, Cambridge.

McHenry, H.M., 1992. Sexual dimorphism in Australopithecus afarensis. J. Hum. Evol. 20, 2132.

Pal, G.P., Routal, R.V., 1991. Relationship between the articular surface area of a bone and the magnitude of stress passing through it. Anat. Rec. 230, 570-574.

Plavcan, J.M., 2000. Inferring social behavior from sexual dimorphism in the fossil record. J. Hum. Evol. 39, 327-344.

Plavcan, J.M., Lockwood, C.A., Kimbel, W.H., Lague, M.R., Harmon, E.H., 2005. Sexual dimorphism in Australopithecus afarensis revisited: how strong is the case for a human-like pattern of dimorphism? J. Hum. Evol. 48, 313-320.

Plavcan, J.M., van Schaik, C.P., 1997. Interpreting hominid behavior on the basis of sexual dimorphism. J. Hum. Evol. 32, 345-374.

Ohman, J.C., Krochta, T.J., Lovejoy, C.O., Mensforth, R.P., Latimer, B., 1997. Cortical bone distribution in the femoral neck of hominoids: implications for the locomotion of Australopithecus afarensis. Am. J. Phys. Anthropol. 104, 117-131.

Reno, P.L., Meindl, R.S., McCollum, M.A., Lovejoy, C.O., 2003. Sexual dimorphism in Australopithecus afarensis was similar to that of modern humans. Proc. Natl. Acad. Sci. U.S.A. 100, 9404-9409.

Reno, P.L., Meindl, R.S., McCollum, M.A., Lovejoy, C.O., 2005. The case is unchanged and remains robust: Australopithecus afarensis exhibits only moderate skeletal dimorphism. J. Hum. Evol. 49, 279-288.

Remis, M.J., 1995. Effects of body size and social context on the arboreal activities of lowland gorillas in the Central African Republic. Am. J. Phys. Anthropol. 97, 413-433. 
Remis, M.J., 1999. Tree structure and sex differences in arboreality among Western Lowland Gorillas (Gorilla gorilla gorilla) at Bai Hokou, Central African Republic. Primates 40, 383396.

Richmond, B.G., Aiello, L.C., Wood, B.A., 2002. Early hominin limb proportions. J. Hum. Evol. $43,529-548$.

Richmond, B.G., Jungers, W.L., 1995. Size variation and sexual dimorphism in Australopithecus afarensis and living hominoids. J. Hum. Evol. 29, 229-245.

Ruff, C.B., 2002. Long bone articular and diaphyseal structure in Old World monkeys and apes. I: locomotor effects. Am. J. Phys. Anthropol. 119, 305-342.

Schmid, P., 1983. Eine rekonstruktion des skelettes von A.L. 288-1 (Hadar) und deren konsequenzen. Folia Primatol. 40, 283-306.

Scott, J.E., Stroik, L.K., 2006. Bootstrap tests of significance and the case for humanlike skeletal-size dimorphism in Australopithecus afarensis. J. Hum. Evol. 51, 422-428.

Senut, B., Tardieu, C., 1985. Functional aspects of Plio-Pleistocene hominid limb bones: implications for taxonomy and phylogeny. In: Delson E. (Ed.), Ancestors: The Hard Evidence. Alan R. Liss, New York, pp. 193-201.

Senut, B., Pickford, M., Gommery, D., Mein, P., Cheboi, K., Coppens, Y., 2001. First hominid from the Miocene (Lukeino formation, Kenya). Comptes Rendus de l'Academie des Sciences, Paris 332, 137-144.

Sinclair, A.R.F., 1986. Migration and hominid bipedalism. Nature 324, 367-368.

Stanford, C.B., 1998. Chimpanzee and Red Colobus. Harvard University Press, Cambridge, MA.

Stern, J.T., Jr., 2000. Climbing to the top: a personal memoir of Australopithecus afarensis. Evol. Anthropol 9, 113-133.

Stern, J.T., Jr., Susman, R.L., 1983. Locomotor anatomy of Australopithecus afarensis. Am. J. Phys. Anthropol. 60, 279-317.

Sugardjito, J., van Hooff, J.A.R.A.M., 1986. Age-sex class differences in the positional behaviour of the Sumatran orang-utan (Pongo pygmaeus abelii) in the Gunung Leuser National Park, Indonesia. Folia Primatol. 47, 14-25.

Tocheri, M.W., Orr, C.M., Larson, S.G., Sutikna, T., Jatmiko, Saptomo E.W., Due, R.A., Djubiantono, T., Morwood, M.J., Jungers, W.L., 2007. The primitive wrist of Homo floresiensis and its implications for hominin evolution. Science 317, 1743-1745. 
Videan, E.N, McGrew, W.C., 2002. Bipedality in chimpanzee (Pan troglodytes) and bonobo (Pan paniscus): testing hypotheses on the evolution of bipedalism. Am. J. Phys. Anthropol. $118,184-190$.

Wang, W.J., Crompton, R.H., Li, Y., Gunther, M.M., 2003. Optimum ratio of upper to lower limb lengths in hand-carrying of a load under the assumption of frequency coordination. J. Biomech. 36, 249-252.

Ward, C.V., 2003. Interpreting the posture and locomotion of Australopithecus afarensis: where do we stand? Yrbk. Phys. Anthropol. 45, 185-215.

Ward, C.V., Kimbel, W.H., Johanson, D.C., 2011. Complete fourth metatarsal and arches in the foot of Australopithecus afarensis. Science 331, 750-753.

Williams, F.L., Amaral, L.Q., Cunningham, D.L., 2010. Carrying the load: is there evidence for infant transport in the human fossil record? Am. J. Phys. Anthropol. Suppl. 50, 245. 


\section{Legends to Figures}

Fig. 1. Ulnar articular surface dimensions (UV1-UV8) are shown on lateral (a) and anterior (b) views of this left ulna. The antebrachial index (RU) is calculated using radius length (RL), shown on a right radius, anterior view (c), and ulna length (UL) shown in (a).

Fig. 2. Intercept-adjusted ratios control for size as well as for allometric effects. A nonzero slope or coefficient may characterize unadjusted ratios $(y / x)$ introducing allometric artifacts into the comparison. Intercept adjusted ratios ( $y x a d j)$ are calculated by first regressing $(y)$ by $(x)$, then subtracting the resulting y-intercept $(a)$ from $(y)$, followed by division by $(x)$, producing a flat line regression with a slope equal to zero indicative of isometry. In other words, as size $(x)$ increases, the ratio of $(y)$ to $(x)$ does not increase.

Fig. 3. Canonical Scores axes of scaled ulnar articular dimensions ( $y x U V a d j)$ and UL account for $93.8 \%$ of the variance. Each taxon is shown with $68 \%$ sample confidence ellipses, including the four estimates for A. afarensis using (1) ulna length for A.L. 438-1 from Drapeau et al. (2005); (2) ulna length for A.L. 438-1 from Kimbel et al. (1994); (3) ulna length for A.L. 288-1 from Haeusler and McHenry (2004); and (4) ulna length for A.L. 288-1 from Kimbel et al. (1994).

Fig. 4. Cluster analysis of scaled ulnar articular dimensions ( $y x U V a d j$ ) shows A.L. 438-1 joins most closely with male H. sapiens. The Hausler and McHenry (2004) A.L. 288-1 estimate for ulna length joins to H. sapiens, G. gorilla and A.L. 438-1 while that from Kimbel et al. (1994) groups with the Pan.

Fig. 5. A comparison of the intercept-adjusted antebrachial index ( $y x R U a d j)$ across taxa demonstrates the relatively low values for $H$. sapiens and $A$. afarensis estimates (d), (e) and (h). Fossil composites for A.L. 288-1 include (a) long radius length from Asfaw et al. (1999) with ulna length from Haeusler and McHenry (2004); (b) long radius length from Asfaw et al. (1999) 
with ulna length from Kimbel et al. (1994); (c) short radius length from Asfaw et al. (1999) with ulna length from Haeusler and McHenry (2004); (d) short radius length from Asfaw et al. (1999) with ulna length from Kimbel et al. (1994); (e) radius length from Schmid (1983) with ulna length from Haeusler and McHenry (2004); and (f) radius length from Schmid (1983) with ulna length from Kimbel et al. (1994). Two combinations for A.L. 438-1 include (g) radius length from this study with ulna length from Kimbel et al. (1994); and (h) radius length from this study with ulna length from Drapeau et al. (2005). Taxon identifiers are positioned on the medians. Boxes represent $50 \%$ of the observations. Whiskers demarcate the terminus of the $95 \%$ confidence intervals. Outliers are denoted by asterisks. 
Table 1. Description of measurements and indices. Measurements taken in mm.

\begin{tabular}{|c|c|c|}
\hline Code & Name & Description \\
\hline UV1 & $\begin{array}{l}\text { Ulnar trochlear notch } \mathrm{ML}^{1} \\
\text { breadth, proximal }\end{array}$ & $\begin{array}{l}\text { Proximal portion of the articular surface at its } \\
\text { maximum mediolateral breadth }\end{array}$ \\
\hline UV2 & $\begin{array}{l}\text { Ulnar trochlear notch ML } \\
\text { breadth, middle }\end{array}$ & $\begin{array}{l}\text { Middle portion of the articular surface at its narrowest } \\
\text { waist, approximates }{ }^{3}\end{array}$ \\
\hline UV3 & $\begin{array}{l}\text { Ulnar trochlear notch ML } \\
\text { breadth, distal }\end{array}$ & $\begin{array}{l}\text { Midpoint of the most medial line of the radial notch to } \\
\text { the most medial point on the articular surface }\end{array}$ \\
\hline UV4 & $\begin{array}{l}\text { Ulnar trochlear notch length, } \\
\text { lateral }\end{array}$ & $\begin{array}{l}\text { Midpoint of the proximal line of the radial notch to the } \\
\text { most proximally projecting point on the olecranon } \\
\text { process }\end{array}$ \\
\hline UV5 & $\begin{array}{l}\text { Ulnar radial notch } \\
\text { anteroposterior length }\end{array}$ & Anteroposterior midline length ${ }^{4}$ \\
\hline UV6 & $\begin{array}{l}\text { Ulnar radial notch } \\
\text { proximodistal length }\end{array}$ & $\begin{array}{l}\text { Proximodistal midline length, taken perpendicular to } \\
\text { radial notch anteroposterior length }{ }^{5}\end{array}$ \\
\hline UV7 & Ulnar head ML breadth & $\begin{array}{l}\text { Maximum mediolateral ulnar head breadth, calipers } \\
\text { held perpendicular to long axis of bone }\end{array}$ \\
\hline UV8 & $\begin{array}{l}\text { Ulnar maximum } \\
\text { anteroposterior head length }\end{array}$ & $\begin{array}{l}\text { Length of ulnar head including the styloid process } \\
\text { taken perpendicular to long axis of bone }{ }^{7}\end{array}$ \\
\hline UL & Maximum ulna length & $\begin{array}{l}\text { Proximal aspect of olecranon process to the distal } \\
\text { terminus of the ulnar styloid process }{ }^{8}\end{array}$ \\
\hline RL & Maximum radius length & $\begin{array}{l}\text { Proximal surface of radial head to the more proximal } \\
\text { point on the radial styloid process }\end{array}$ \\
\hline RU & Antebrachial index & $\begin{array}{l}\text { Intercept-adjusted maximum radius length }(\mathrm{RL}) / \\
\text { maximum ulna length (UL) }\end{array}$ \\
\hline $\begin{array}{l}{ }^{1} \mathrm{ML}= \\
\text { (Knuss } \\
40 \text { (Kn } \\
{ }^{9} \text { Numb }\end{array}$ & $\begin{array}{l}\text { iolateral; }{ }^{2} \text { approximates Nun } \\
\text {, 1967); }{ }^{4} \text { Number } 34 \text { (Knus } \\
\text { lann, 1967); }{ }^{7} \text { Number } 39 \text { (Kn } \\
\text { (Knussmann, 1967) }\end{array}$ & $\begin{array}{l}\text { ber } 32 \text { (Knussmann, 1967); }{ }^{3} \text { approximates Number } 26 \\
\text { nann, 1967); }{ }^{5} \text { Number } 35 \text { (Knussmann, 1967); }{ }^{6} \text { Number } \\
\text { Issmann, 1967); }{ }^{8} \text { Number } 21 \text { (Knussmann, 1967); }\end{array}$ \\
\hline
\end{tabular}


Table 2. Fossil forearm bone length estimates for A.L. 288-1 and A.L. 438-1

\begin{tabular}{ll|lc}
\hline \multicolumn{2}{c|}{ Radius } & \multicolumn{2}{c}{ Ulna } \\
\hline A.L. $288-1$ & $174 \mathrm{~mm}^{1}$ & A.L. $288-1$ & $220 \mathrm{~mm}^{4}$ \\
A.L. $288-1$ & $203 \mathrm{~mm}^{2}$ & A.L. $288-1$ & $191 \mathrm{~mm}^{5}$ \\
A.L. $288-1$ & $215 \mathrm{~mm}^{2}$ & A.L. $438-1$ & $268 \mathrm{~mm}^{4}$ \\
A.L. $438-1$ & $259.3 \mathrm{~mm}^{3}$ & A.L. $438-1$ & $278 \mathrm{~mm}^{6}$ \\
\hline
\end{tabular}

${ }^{1}$ Schmid (1983); ${ }^{2}$ Asfaw et al. (1999); ${ }^{3}$ Derived from a linear regression of radius and ulna from the extant samples used in this study $(\mathrm{n}=244)$; ${ }^{4}$ Kimbel et al. (1994), ${ }^{5}$ Haeusler and McHenry (2004); ${ }^{6}$ Drapeau et al. (2005). 
Table 3. Descriptive statistics by taxon and $\operatorname{sex}^{1}$ for all scaled ulnar articular surface dimensions ( $y x U V a d j)$ and the antebrachial index ( $y x R U a d j$ ) (see Table 1 and text for definitions).

\begin{tabular}{lcccccccccr}
\hline Taxon and sex & & UV1 & UV2 & UV3 & UV4 & UV5 & UV6 & UV7 & UV8 & RU \\
\hline A. afarensis F (A.L. 288-1) & Mean & 0.073 & 0.127 & 0.141 & 0.052 & 0.052 & 0.070 & 0.090 & 0.027 & 101.672 \\
& SD & 0.007 & 0.013 & 0.014 & 0.005 & 0.005 & 0.007 & 0.009 & 0.003 & 12.133 \\
A. afarensis M (A.L. 438-1) & Mean & 0.090 & 0.121 & 0.128 & 0.057 & 0.052 & 0.081 & 0.088 & 0.033 & 98.884 \\
& $\mathrm{SD}$ & 0.020 & 0.003 & 0.003 & 0.001 & 0.001 & 0.002 & 0.002 & 0.001 & 2.561 \\
H. sapiens $\mathrm{F}(\mathrm{n}=19)$ & Mean & 0.089 & 0.122 & 0.132 & 0.074 & 0.054 & 0.082 & 0.092 & 0.038 & 96.146 \\
& $\mathrm{SD}$ & 0.007 & 0.006 & 0.007 & 0.013 & 0.004 & 0.008 & 0.007 & 0.005 & 0.878 \\
H. sapiens $\mathrm{M}(\mathrm{n}=32)$ & Mean & 0.088 & 0.119 & 0.125 & 0.066 & 0.055 & 0.080 & 0.086 & 0.036 & 97.335 \\
& $\mathrm{SD}$ & 0.008 & 0.014 & 0.007 & 0.013 & 0.006 & 0.008 & 0.006 & 0.008 & 1.270 \\
G. gorilla $\mathrm{F}(\mathrm{n}=33)$ & $\mathrm{Mean}$ & 0.084 & 0.136 & 0.136 & 0.064 & 0.059 & 0.083 & 0.093 & 0.035 & 98.574 \\
& $\mathrm{SD}$ & 0.007 & 0.010 & 0.007 & 0.007 & 0.006 & 0.006 & 0.005 & 0.008 & 1.316 \\
G. gorilla $\mathrm{M}(\mathrm{n}=55)$ & Mean & 0.093 & 0.134 & 0.139 & 0.074 & 0.059 & 0.083 & 0.096 & 0.037 & 97.631 \\
& $\mathrm{SD}$ & 0.008 & 0.014 & 0.008 & 0.007 & 0.006 & 0.008 & 0.005 & 0.005 & 1.252 \\
P. troglodytes $\mathrm{F}(\mathrm{n}=20)$ & Mean & 0.074 & 0.105 & 0.119 & 0.055 & 0.052 & 0.696 & 0.089 & 0.028 & 99.640 \\
& $\mathrm{SD}$ & 0.007 & 0.006 & 0.006 & 0.009 & 0.006 & 0.010 & 0.005 & 0.004 & 1.448 \\
P. troglodytes $\mathrm{M}(\mathrm{n}=29)$ & Mean & 0.075 & 0.103 & 0.122 & 0.062 & 0.053 & 0.068 & 0.089 & 0.029 & 98.746 \\
& $\mathrm{SD}$ & 0.006 & 0.011 & 0.007 & 0.007 & 0.005 & 0.009 & 0.006 & 0.003 & 1.062 \\
P. pygmaeus $\mathrm{F}(\mathrm{n}=23)$ & Mean & 0.058 & 0.091 & 0.106 & 0.038 & 0.047 & 0.069 & 0.078 & 0.028 & 99.894 \\
& $\mathrm{SD}$ & 0.005 & 0.011 & 0.005 & 0.005 & 0.004 & 0.005 & 0.005 & 0.005 & 1.451 \\
P. pygmaeus $\mathrm{M}(\mathrm{n}=13)$ & Mean & 0.062 & 0.084 & 0.108 & 0.046 & 0.047 & 0.069 & 0.079 & 0.029 & 99.605 \\
& $\mathrm{SD}$ & 0.004 & 0.010 & 0.005 & 0.005 & 0.003 & 0.006 & 0.005 & 0.004 & 0.956 \\
\hline
\end{tabular}

${ }^{1}(\mathrm{~F}=$ female; $\mathrm{M}=$ male $)$

${ }^{2}$ Means and standard deviations for $A$. afarensis were calculated using four estimates for the ulna articular dimensions ( $y x U V a d j)$ and eight estimates for the antebrachial index ( $y x R U a d j)$. 
Table 4. Classification rates derived from a discriminant function analysis ${ }^{1}$.

\begin{tabular}{lrr}
\hline Taxon & $\begin{array}{r}\text { Classification } \\
\text { rates }\end{array}$ & $\begin{array}{r}\text { Jack-knifed } \\
\text { Classification } \\
\text { rates }\end{array}$ \\
\hline A. afarensis & $50 \%$ & $50 \%$ \\
H. sapiens $\mathrm{F}$ & $72 \%$ & $67 \%$ \\
H. sapiens $\mathrm{M}$ & $81 \%$ & $65 \%$ \\
G. gorilla $\mathrm{F}$ & $100 \%$ & $100 \%$ \\
G. gorilla $\mathrm{M}$ & $100 \%$ & $100 \%$ \\
P. troglodytes $\mathrm{F}$ & $68 \%$ & $47 \%$ \\
P. troglodytes $\mathrm{M}$ & $69 \%$ & $59 \%$ \\
P. pygmaeus $\mathrm{F}$ & $100 \%$ & $96 \%$ \\
P. pygmaeus $\mathrm{M}$ & $100 \%$ & $100 \%$ \\
\hline I (F = female; $\mathrm{M}=$ male) & &
\end{tabular}


Table 5. Canonical scores (CS) structure matrix for ( $y x U V a d j)$ and ulna length (UL).

\begin{tabular}{lrr}
\hline Variable & CS Axis 1 & CS Axis 2 \\
\hline UV1 & 0.212 & 0.457 \\
UV2 & -0.182 & 0.250 \\
UV3 & -0.548 & 0.285 \\
UV4 & 0.222 & 0.476 \\
UV5 & -0.271 & 0.228 \\
UV6 & -0.195 & 0.036 \\
UV7 & -0.322 & -0.314 \\
UV8 & -0.008 & 0.001 \\
UL & -1.258 & -0.207 \\
\hline
\end{tabular}


Table 6. Tukey's post-hoc test results from an ANOVA of the antebrachial index ( $y x R U a d j)$.

\begin{tabular}{lc}
\hline Taxon comparisons & $P$ value \\
\hline G. gorilla-H. sapiens & $<0.001$ \\
G. gorilla-P. troglodytes & $<0.001$ \\
G. gorilla-P. pygmaeus & $<0.001$ \\
H. sapiens-P. troglodytes & $<0.001$ \\
H. sapiens-P.pygmaeus & $<0.001$ \\
P. troglodytes-P.pygmaeus & 0.096 \\
\hline
\end{tabular}


Table 7. T-test results between females and males for each extant taxon for scaled ulna articular dimensions ( $y x U V a d j)$ and antebrachial index $(y x R U a d j)^{1}$.

\begin{tabular}{lrrrrrrrrr}
\hline Taxon & UV1 & UV2 & UV3 & UV4 & UV5 & UV6 & UV7 & UV8 & RU \\
\hline H. sapiens & 0.516 & 0.242 & $<\mathbf{0 . 0 0 1}$ & $\mathbf{0 . 0 3 8}$ & 0.300 & 0.280 & $\mathbf{0 . 0 0 2}$ & 0.221 & $<\mathbf{0 . 0 0 1}$ \\
G. gorilla & $<\mathbf{0 . 0 0 1}$ & 0.489 & 0.153 & $<\mathbf{0 . 0 0 1}$ & 0.912 & 0.940 & $\mathbf{0 . 0 3 2}$ & 0.261 & $\mathbf{0 . 0 0 1}$ \\
$P$. & 0.064 & 0.394 & 0.133 & $\mathbf{0 . 0 0 5}$ & 0.514 & 0.628 & 0.997 & 0.522 & $\mathbf{0 . 0 2 5}$ \\
troglodytes & & & & & & & & & \\
$P$. & $\mathbf{0 . 0 1 3}$ & 0.062 & 0.412 & $<\mathbf{0 . 0 0 1}$ & 0.688 & 0.986 & 0.375 & 0.241 & 0.489 \\
pygmaeus & & & & & & & & &
\end{tabular}

${ }^{1}$ Significant results are in bold. 
Figure 1

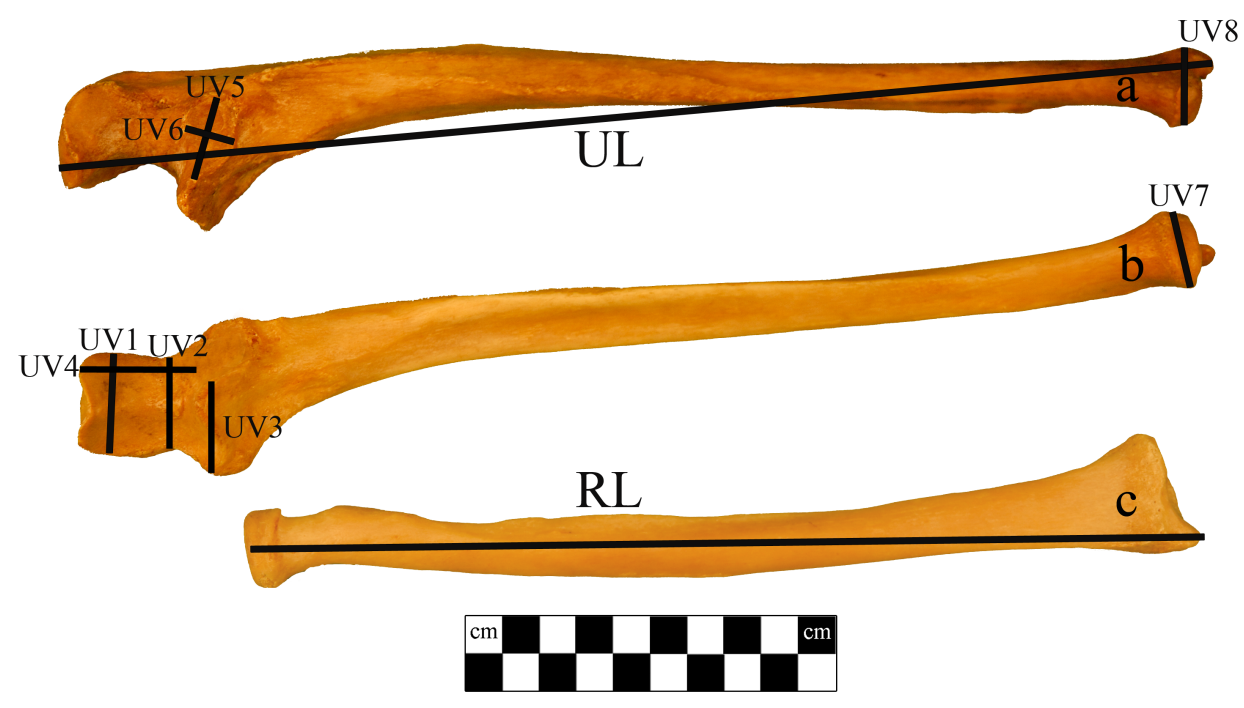


Figure 2

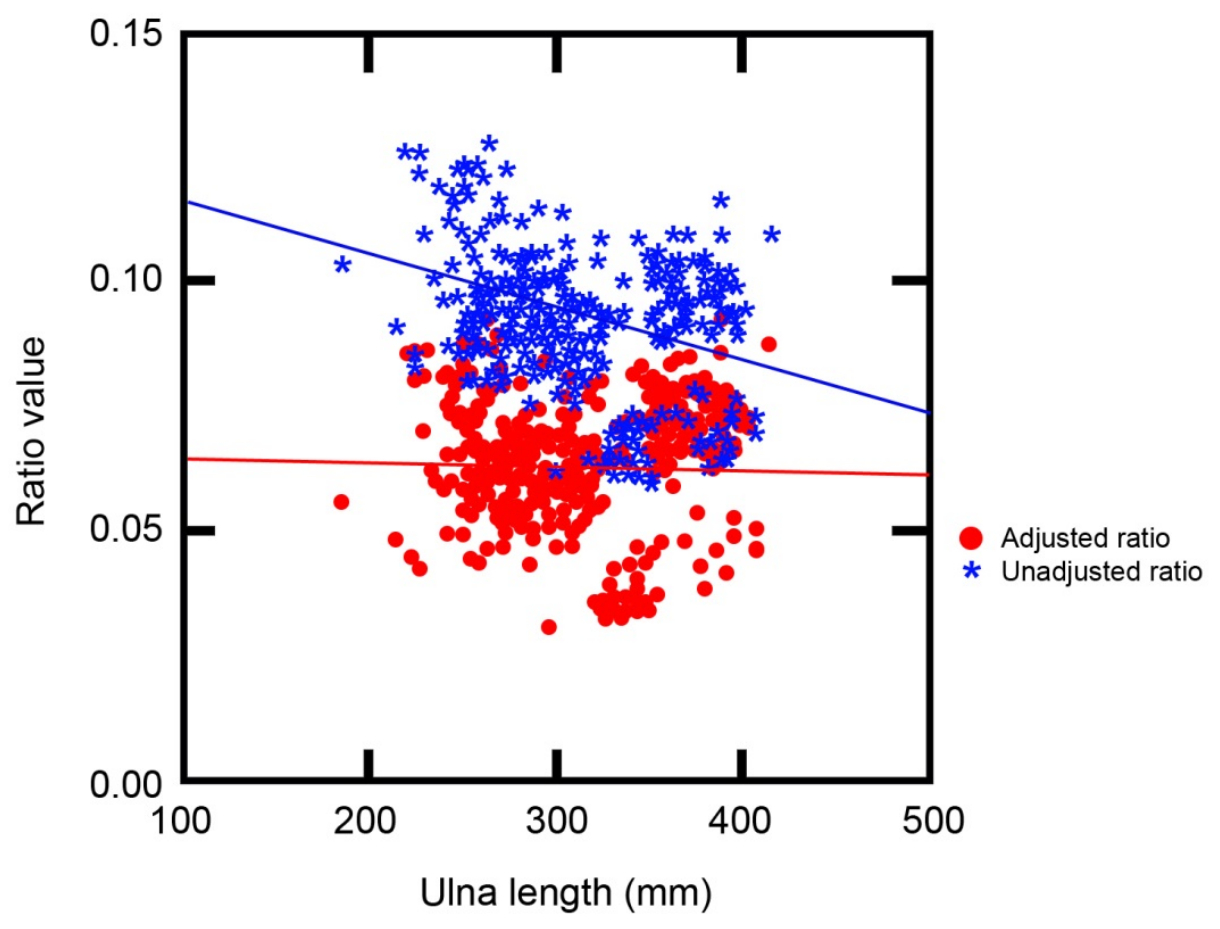


Figure 3

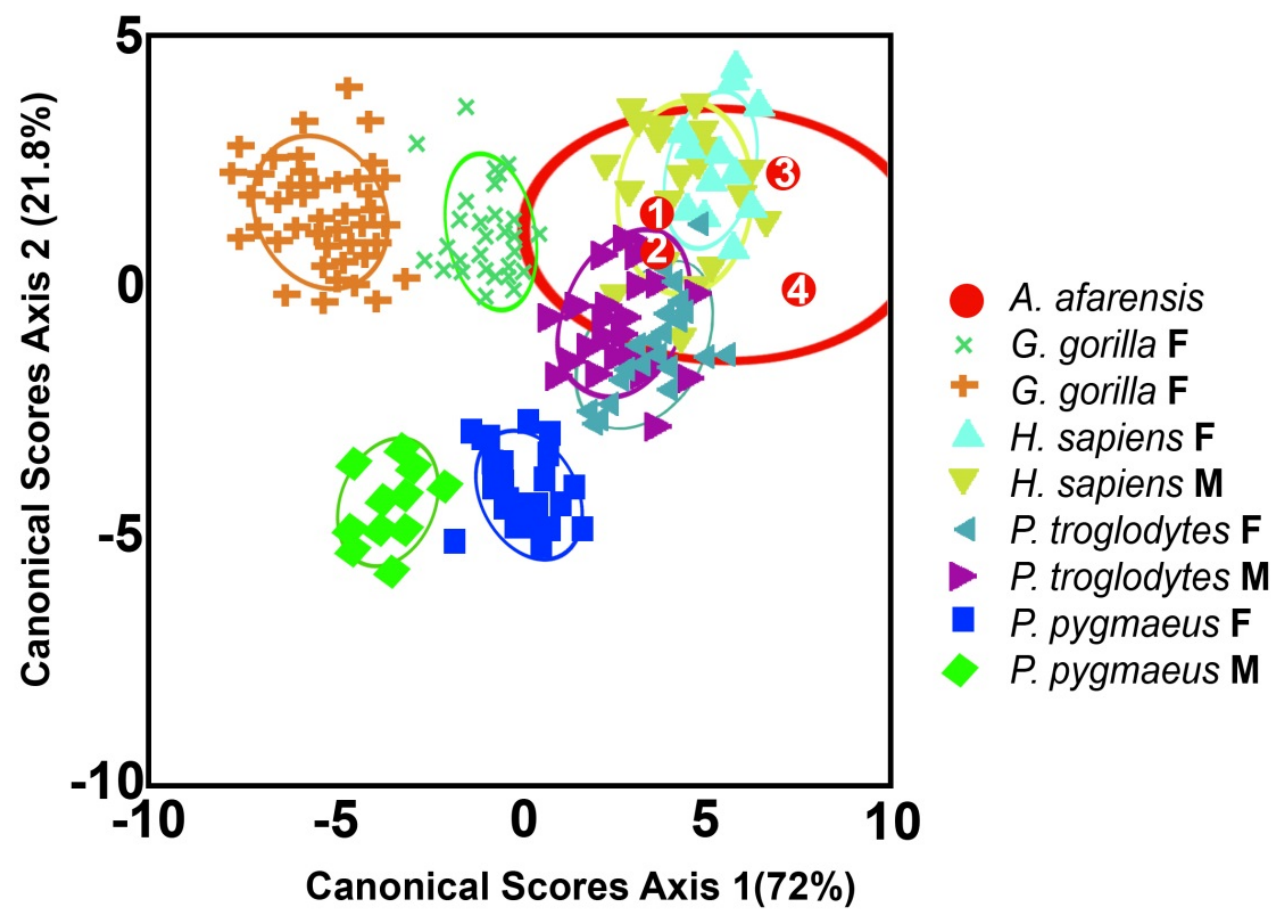


Figure 4

Cluster Tree

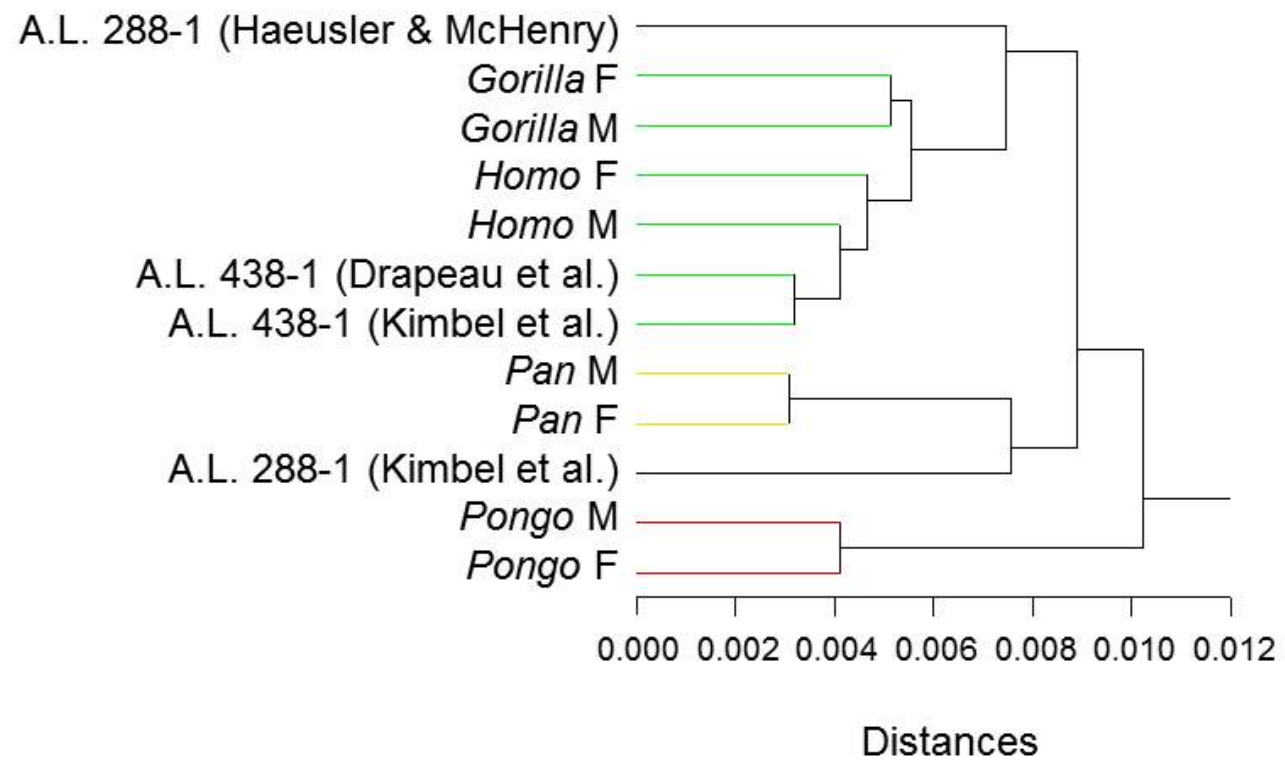


Figure 5

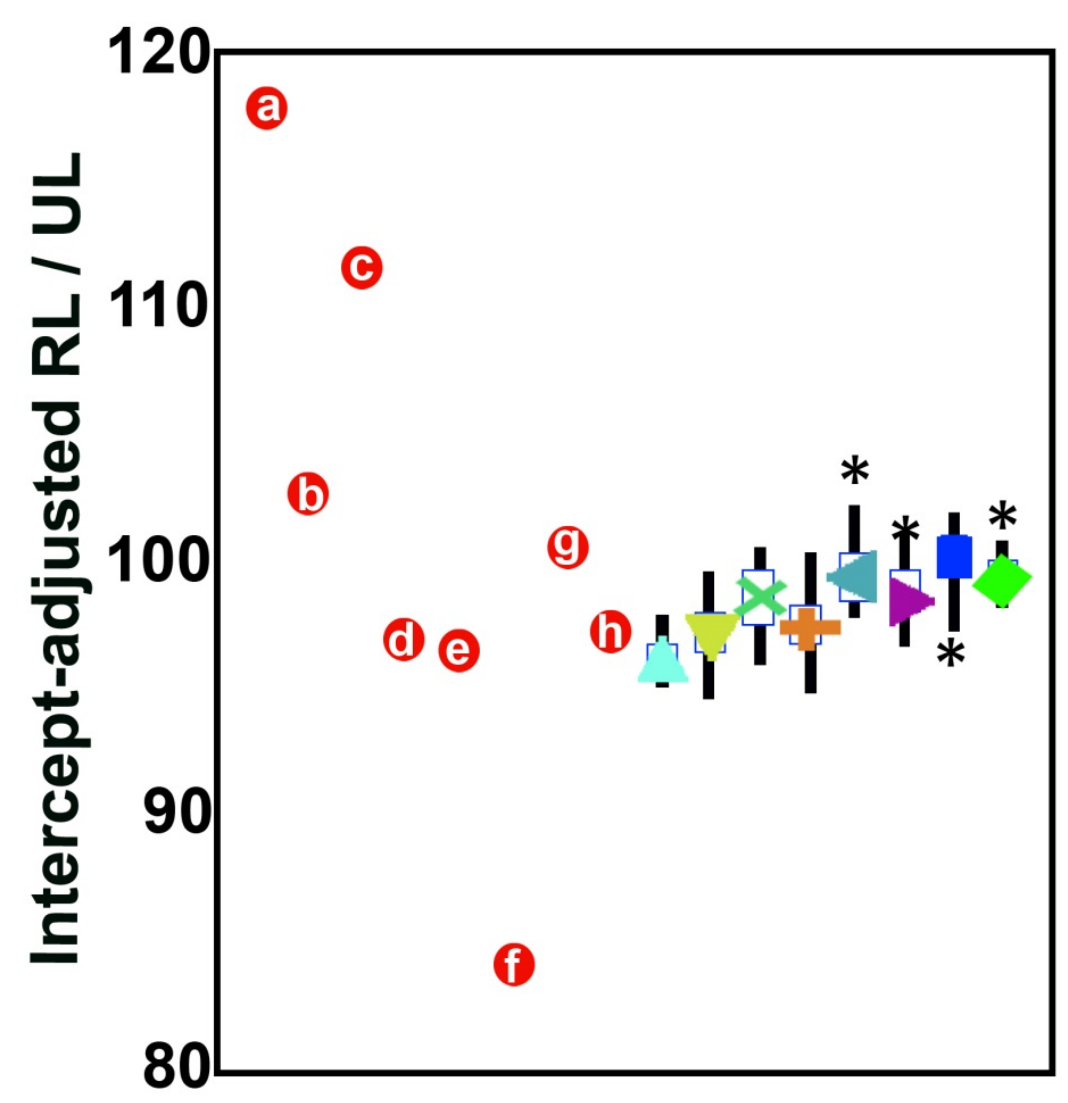

A. afarensis

$H$. sapiens $\mathbf{F}$

$\nabla$ H. sapiens $\mathbf{M}$

$\times$ G. gorilla $\mathbf{F}$

+ G. gorilla M

$\triangle$ P. troglodytes $\mathbf{F}$

- P. troglodytes $\mathbf{M}$

- P. pygmaeus $\mathbf{F}$

P. pygmaeus $\mathbf{M}$ 